Mackin, P., Bishop, D., Watkinson, H., et al (2007) Metabolic disease and cardiovascular risk in people treated with antipsychotics in the community. British Journal of Psychiatry, 191, 23-29.

Osborn, D. P. J., Nazareth, I. \& King, M. B. (2006) Risk for coronary heart disease in people with severe mental illness: cross-sectional comparative study in primary care. British Journal of Psychiatry, 188, 27I-277.

A. Banerjee Postgraduate Institute of Medical Education and Research, Chandigarh, India. Email: dr.banerjee@gmail.com

D. Basu Postgraduate Institute of Medical Education and Research, Chandigarh, India doi: 10.I192/bjp.191.6.563a

Authors' reply Banerjee \& Basu are correct to point out that our study does not have a case-control design in the purest epidemiological sense, that is a study in which patients who have developed a disease are identified and their past exposure to aetiological factors is compared with that of controls. Our study is conceptually similar to the case-control design, although we accept that both our study and case-control studies are inherently vulnerable to methodological weaknesses as discussed recently (Lee et al, 2007). We selected individuals who had had a diagnosis of severe mental illness and antipsychotic treatment to ascertain whether this population was at increased risk for cardio-vascular and metabolic disease compared with a control group.

We also accept, and acknowledge in our paper, that the sample size is relatively small. However, we found highly statistically significant differences between patients and controls across a number of outcomes. The analysis of effect of diagnosis, type of antipsychotic medication and smoking status was not a primary aim but was a secondary analysis. Increasing the sample size further might have added power to the study to detect differences in these variables. Notwithstanding, emerging evidence from studies in people with bipolar disorders points to an excess of cardiovascular and metabolic disease comparable to that in schizophrenia, suggesting that the similar rates across our diagnostic groups is a true finding.

Banerjee \& Basu question the appropriateness of the term 'severe mental illness' The vast majority $(75.6 \%)$ of patients had a diagnosis of schizophrenia, bipolar disorder or schizoaffective disorder. Many in the 'other' category (comprising 24.4\%) had experienced psychotic depression and other severe depressive disorders requiring antipsychotic treatment. Although the use of the word 'severe' may be questioned, we are confident that this is appropriate.

We await larger, prospective studies designed specifically to tease out the aetiological factors that contribute to an excess of cardiovascular and metabolic risk and ultimately an excess mortality rate in this population. We hope our study has gone some way to highlighting the need for vigilant monitoring and appropriate intervention in this high-risk group.

Lee, W., Bindman, J., Ford, T., et al (2007) Bias in psychiatric case-control studies: literature survey. British Journal of Psychiatry, 190, 204-209.

P. Mackin Institute of Neuroscience,

Newcastle University, Newcastle, UK.

Email: paul.mackin@ncl.ac.uk

P. Gallagher Institute of Neuroscience,

Newcastle University, Newcastle, UK

doi: 10.II92/bjp.191.6.564

\section{Psychiatry and faith-based organisations}

Leavey \& King (2007) provide a usefu overview of the relationship between the clergy and psychiatry. Although I wholeheartedly agree that there should be partnerships between psychiatry and religious sectors, I found the discussion to be onesided. Leavey \& King say little about what religion can offer psychiatry. It is well recognised that religious states are often misdiagnosed as mental illness (Dein, 2004). Religious professionals can play a pivotal role in teaching mental health professionals about normative religious experiences and thus enable them to make better informed diagnoses. It is not just that religious professionals need to be educated about mental illness but it is also vital that psychiatrists understand religious experience.

Of course ideas about mental illness reflecting sin still exist in some religious communities, but in my own fieldwork among Orthodox Jews and Pentecostal Christians it is evident that rabbis and pastors increasingly recognise mental illness as a state independent of moral indiscretion. Even in communities where extreme religious experiences, such as hearing God's voice, are prevalent, religious leaders are able to differentiate these experiences from the symptoms of severe mental disorder (Dein
\& Littlewood, 2007). Similarly they are able to differentiate psychoses from states of spirit possession (which themselves require stringent criteria for their diagnosis within the religious context).

Beyond this, there is emerging evidence that religion can play an important role in facilitating coping with life stressors (Pargament, 1997). Mental health professionals need to be knowledgeable about the circumstances in which referrals to religious professionals are appropriate. They should be aware that for religious believers, prayer and ritual may play a central role in the healing process. Of course involvement in such activities may influence pathways to care but there is ample evidence that religious and biomedical forms of healing can work well together: biomedicine healing the body and religion healing the soul (Littlewood \& Dein, 1995).

Finally I take issue with the statement that biomedical and spiritual models of illness are necessarily conflicting. Spirituality and biomedicine offer different types of explanations for patients' problems. The art of medicine should be to learn how to combine different treatments in order to provide more holistic care to patients.

Dein, S. (2004) Working with patients with religious beliefs. Advances in Psychiatric Treatment, 10, 287-294.

Dein, S. \& Littlewood, R. (2007) The voice of God. Anthropology and Medicine, 14, 213-228.

Leavey, G. \& King, M. (2007) The devil is in the detail: partnerships between psychiatry and faith-based organisations. British Journal of Psychiatry, 191, 97-98.

Littlewood, R. \& Dein, S. (1995) The effectiveness of words: religion and healing among the Lubavitch of Stamford Hill. Culture, Medicine and Psychiatry, I, 339-383.

Pargament, K. (1997) The Psychology of Religion and Coping: Theory, Research, Practice. Guilford Press.

S. Dein Centre for Behavioural and Socia Sciences in Medicine, University College London, Charles Bell House, 67 Riding House Street, London WIN 8AA, UK. Email: s.dein@ucl.ac.uk

doi: 10.II92/bjp.19I.6.564a

Faith and other religious terms are still not considered an explicit language of psychiatry. Faith is a multilayered phenomenon, involving a belief about things of which we are uncertain accompanied by an expectancy and/or conviction (Clarke, 2003). The Bible defines faith as being sure of what people hope for and certain of what they do not see (Hebrews 11:1). Faith is considered a nebulous concept and its 
benefit is beyond objective scientific measurement. Despite this the World Health Organization clearly stresses the value of concepts such as faith, hope and compassion in the healing process from any illness (World Health Organization, 1998). Religions based on strong faith and beliefs have evolved and persisted over centuries, and people do turn to religion when coping with life stressors (Pargament, 1997). If this spiritual craving is to be utilised for promoting better mental health and holistic care, stronger collaboration between psychiatrists and religious professionals is important (Rattray, 2002; Dein, 2004).

It is encouraging to note, despite the constant suspicion between psychiatry and religion (Bhugra, 1997), the incorporation of religious principles based on faith into treatment strategies especially in psychotherapy, and this should be welcomed. Christian principles have been effective in cognitive therapy and help to improve spiritual well-being (Lipsker \& Oordt, 1990; Hawkins et al, 1999). The thirdwave cognitive-behavioural therapies such as dialectical behavioural therapy, acceptance and commitment therapy, and mindfulness-based cognitive therapy are closer to religious belief systems and practices (Andersson \& Asmundson, 2006). Zen Buddhist ideas have been woven into the fabric of dialectical behavioural therapy (Robins, 2002). Acceptance and commitment therapy connects with the Buddhist philosophy and practices in accepting the four noble truths and the eight-fold noble path (Hayes, 2002). The mindfulness-based therapies have stronger associations with Buddhism, its empirical database and its application for stress reduction, health promotion and improved personal functioning (Robins, 2002). This gives an early hope that mainstream psychiatry and religions with strong faith and belief systems can work together to ameliorate psychopathology and improve the well-being of patients.

Andersson, G. \& Asmundson, G. (2006) CBT and religion. Cognitive Behaviour Therapy, 35, $1-2$.
Bhugra, D. (1997) Psychiatry and Religion: Context, Consensus and Controversies. Routledge.

Clarke, C. (2003) Faith and hope: religion and spirituality. Australasian Psychiatry, II, 164-168.

Dein, S. (2004) Working with patients with religious beliefs. Advances in Psychiatric Treatment, 10, 287-294.

Hawkins, R. S., Tan, S. Y. \& Turk, A. A., et al (1999)

Secular vs Christian in-patient CBT programs. Impact on depression and spiritual well being. Journal of Psychology and Theology, 27, 309-33l.

Hayes, S. (2002) Buddhism and ACT. Cognitive and Behavioural Practice, 9, 58-66.

Lipsker, L. \& Oordt, R. M. (1990) Treatment of depression in adolescents: a Christian cognitive behaviour therapy approach. Journal of Psychology and Christianity, 9, 25-33.

Pargament, K. I. (1997) The Psychology of Religion and Coping. Guilford Press.

Rattray, L. H. (2002) Significance of the chaplain within the mental health care team. Psychiatric Bulletin, 26. $|90-19|$

Robins, C. (2002) Zen principles and mindfulness practice in DBT. Cognitive and Behavioural Practice, $\mathbf{9}$, 50-57.

World Health Organization (1998) WHOQOL and Spirituality, Religiousness and Personal Beliefs. WHO.

S. Masil Department of Liaison Psychiatry, Birmingham and Solihull Mental Health NHS Trust, Newbridge House, 130 Hob Moor Road, Small Heath, Birmingham BI0 9JH, UK.

Email: gmashil@yahoo.co.uk

doi: 10.I192/bjp.191.6.564b

Authors' reply: Dr Dein argues that our editorial (Leavey \& King, 2007) on collaboration between psychiatry and religion is biased because we failed to discuss what religion has to offer psychiatry. We feel that many faith-based organisations and their clergy contribute much towards human welfare and healing and we would have been happy to discuss this in more detail. However, the focus of the paper was to highlight the potential barriers and dangers arising from partnerships between religion and psychiatry. Our own research with clergy has helped clarify some of these issues (Leavey, 2007; Leavey et al, 2007). Thus, clergy of all sorts find themselves perplexed by people with mental health problems and appear to be generally untrained and unsupported by both their own organisations and by mental health services. Although some clergy are able to distinguish religious from psychiatric phenomena, others are not. Dr Dein's reference to his study of lay members of a White Pentecostal congregation does not relate to this issue. Moreover, we did not suggest that biomedical and spiritual models of illness necessarily conflict but in some instances, and among some religious groups, they do. To treat faith communities and their clergy as homogeneous entities is somewhat simplistic. Dr Dein advocates a more holistic approach in medical care, but does he intend this to extend to exorcism and deliverance rituals? This question touches on the central concern of our editorial. We like to talk about inclusivity in psychiatry but it becomes more problematic when clinicians find themselves encouraged to engage with some of the less mainstream aspects of spirituality and religion.

Although we agree with Dr Masil that religion and spirituality, or in his own terms 'faith', should be of greater interest to psychiatric practice and research, we cannot agree that 'its benefit is beyond objective scientific measurement'. Although problems of definition and measurement exist, many health studies of this kind have been undertaken, particularly in the USA where there is less hostility to research on spirituality and health than in the UK.

Leavey, G. (2007) UK clergy and people in mental distress: community and patterns of pastoral care. Transcultural Psychiatry, in press.

Leavey, G., Loewenthal, K. \& King, M. (2007)

Challenges to sanctuary: the clergy as a resource for mental health care in the community. Social Science and Medicine, 65, 548-559.

G. Leavey Research \& Development Department, St Ann's Hospital, St Ann's Road, London NI5 3TH, UK.

Email: gerard.leavey@beh-mht.nhs.uk

M. King Department of Mental Health Sciences, University College London, London, UK

doi: I0.II92/bjp.I9I.6.565 